\title{
Effects of Coconut Chaff on the Physicochemical and Enzyme Activity in Coastal Soil
}

\author{
Xiao Deng ${ }^{1,2,3}$, Chunyuan $\mathrm{Wu}^{1,2,3}$, Qinfen $\mathrm{Li}^{1,2, *}$ \\ ${ }^{1}$ Environment and Plant Protection Institute, Chinese Academy of Tropical Agricultural Sciences, Haikou, 571101, China. \\ ${ }^{2}$ National Agricultural Experimental Station for Agricultural Environment, Danzhou, 571737, China. \\ ${ }^{3}$ Hainan Key Laboratory of Tropical Eco-Circular Agriculture, Haikou, 571101, China.
}

How to cite this paper: Xiao Deng, Chunyuan Wu, Qinfen Li. (2021) Effects of Coconut Chaff on the Physicochemical and Enzyme Activity in Coastal Soil. Engineering Advances, 1(1), 16-20. DOI: 10.26855/ea.2021.06.003

Received: January 25, 2021

Accepted: February 24, 2021

Published: March 25, 2021

*Corresponding author: Qinfen Li, Environment and Plant Protection Institute, Chinese Academy of Tropical Agricultural Sciences, Haikou, 571101, China; National Agricultural Experimental Station for Agricultural Environment, Danzhou, 571737, China. Email: qinfenli2005@163.com

\begin{abstract}
The coconut chaff and coastal soil were used as soil improvement material and the improved object, respectively. Using pot experiment of planting water spinach to study the improvement effect of the coconut chaff on coastal soil under the conditions without chemical fertilizer utilization. Five treatments were designed by mixing the coconut chaff and coastal soil in different volume ratios of $0: 20,1: 20,2: 20,3: 20$ and $4: 20$. The results showed that adding the coconut chaff could obviously promote the growth of water spinach, and the average number of leaves, weight per plant and root weight per plant were increased by $11.3 \%-22.5 \%$, $40.0 \%-47.5 \%$, and $106 \%-175 \%$, respectively. And the soil $\mathrm{pH}$ value was changed from acidity to neutral. The contents of organic matter, total nitrogen, available phosphate and available potassium of coastal soil were increased by $11.1 \%-28.1 \%, 31.3 \%-35.6 \%, 13.0 \%-23.5 \%$ and $9.9 \%-44.8 \%$, respectively. The activities of urease, catalase and acid invertase of coastal soil were increased by $0.3 \%-15.1 \%, 18.7 \%-35.1 \%$ and $47.9 \%-158 \%$, respectively. Especially, the treatments with the addition ratios of 2:20-4:20 could significantly improve the soil $\mathrm{pH}$ value and increase the soil nutrient contents and enzyme activities $(p<0.05)$. It was proved that adding the coconut chaff in the right proportion can improve the physicochemical properties of coastal soil and achieve the purpose of soil improvement.
\end{abstract}

\section{Keywords}

Coconut chaff, Coastal soil, Soil nutrient, Soil enzyme activity, Water spinach

\section{Introduction}

In recent years, soil quality decline is more and more serious, and the area of arable land decreases year by year due to the unreasonable use of cultivated land by human beings. In addition, the content of soil organic matter was sharply decreased and the soil-borne diseases are seriously occurred due to massive application of chemical fertilizer, which will lead to low crop yield and poor soil quality [1]. The coastal soil has poor water and fertilizer retention ability, on account of affecting by the characteristics of sandy soil, which is easy to be leached and its agricultural production efficiency is even lower. Therefore, compared with other types of soil, it is more urgent to strengthen the improvement and utilization of coastal soil. At present, it is generally believed that the biological measures are the most effective ways to improve coastal saline soil in all kinds of technical measures. Applying organic fertilizer can change soil physical properties, improve soil aggregates and increase crop yield in the process of improvement on saline soil. The application of organic fertilizer can also increase the activity and quantity of soil microbial, promote the migration and transformation of salts in the soil and reduce salt content [2,3]. The coconut chaff with a variety of uses is mainly composed of cellulose, hemicellulose and other natural polymer substances, belonging to the pure natural biomass medium, is a kind of renewable biomass resources containing potassium, calcium, nitrogen, phosphorus, magnesium and other nutrient ele- 
ments. However, researches on the improvement of coastal soil by the coconut chaff have not been reported. The objective of this study is to screen the biomaterials that can improve coastal soil and to determine the optimal application ratio. The results of this study will provide theoretical support for improving soil quality and promoting soil sustainable utilization.

\section{Materials and Methods}

The tested soil was collected from Nanxi Village (N 1959.014', E $\left.110^{\circ} 37.453^{\prime}\right)$, Wenchang City, Hainan Province. The soil belongs to loamy sandy soil and acid soil. Soil samples were taken from $0-20 \mathrm{~cm}$ tillage layer by applying five point sampling method. Samples were stored in a plastic bag and taken to the laboratory on the same day, the plant roots and stones were removed, and samples were passed through a $2 \mathrm{~mm}$ sieve after air drying. The tested coconut chaff was from Danzhou agricultural production base of Hainan University. The tested plant was water spinach. The pot experiment was conducted in the greenhouse of Haikou experimental base of Chinese Academy of Tropical Agricultural Sciences from May to July in 2019. Five treatments were designed by mixing the coconut chaff and coastal soil in different volume ratios of 0:20, 1:20, 2:20, 3:20 and 4:20. Each treatment was repeated 3 times. The cultivation conditions and management methods of each pot were same. All the coconut chaff and air drying soil were directly mixed for planting water spinach under conditions without chemical fertilizer utilization, and watered one time a day. Ten plants with the same growth status were remained to observe in each pot after seeds sprouting. The potted soil samples were collected after the harvest of water spinach, passed through a $1 \mathrm{~mm}$ sieve after air drying to analyze the $\mathrm{pH}$ value, the contents of organic matter (SOM), total nitrogen (TN), available phosphate (AP), available potassium (AK) in soil, and passed through a 35 mesh sieve to measure the activities of soil urease (UE), catalase (CAT), acid phosphatase (ACP) and acid invertase (AI). All the soil physicochemical indexes were determined by reference to the agricultural industry standards. All kinds of soil enzyme activities were used Kit (Suzhou Branch Ming Biotechnology Co., Ltd., www.cominbio.com) to analyze. Descriptive statistics for estimation of means and standard deviations of samples were conducted using Excel 2010. Significant differences were analyzed by Duncan’s method.

\section{Results and Discussion}

Table 1 showed that the growth of water spinach was significantly promoted after adding the coconut chaff at 1:20-4:20 in coastal soil. The average number of leaves per plant was increased by $11.3 \%-22.5 \%(P<0.05)$. The average weight per plant was increased by $40.0 \%-47.5 \%(P<0.05)$. The average root weight per plant was increased by 106\%-175\% $(P<0.01)$.

Table 1. Effects of coconut chaff on growth of water spinach in coastal soil

\begin{tabular}{cccc}
\hline Treatment & Leaf number & Plant weight (g/plant) & Root weight (g/plant) \\
\hline $0: 20$ & $7.1 \pm 0.3$ c B & $1.60 \pm 0.12 \mathrm{~b} \mathrm{~B}$ & $0.16 \pm 0.02 \mathrm{~b} \mathrm{~B}$ \\
$1: 20$ & $7.9 \pm 0.5 \mathrm{~b} \mathrm{AB}$ & $2.24 \pm 0.58$ a AB & $0.36 \pm 0.07 \mathrm{a} \mathrm{A}$ \\
$2: 20$ & $8.2 \pm 0.2 \mathrm{ab} \mathrm{A}$ & $2.33 \pm 0.16$ a AB & $0.33 \pm 0.08$ a A \\
$3: 20$ & $8.7 \pm 0.4 \mathrm{a} \mathrm{A}$ & $2.36 \pm 0.09$ a A & $0.44 \pm 0.09$ a A \\
$4: 20$ & $8.7 \pm 0.5$ a A & $2.28 \pm 0.18$ a AB & $0.36 \pm 0.05$ a A \\
\hline
\end{tabular}

Note: Different lower case letters and upper case letters in each column indicate significant differences at $P<0.05$ and $P<0.01$, respectively.

The $\mathrm{pH}$ value of coastal soil was obviously improved after adding the coconut chaff under the conditions without chemical fertilizer utilization (Figure 1). The $\mathrm{pH}$ value was 6.36 in coastal soil without adding the coconut chaff, belonging to acid soil. However, the $\mathrm{pH}$ values were 7.13-7.41 in the treatments with adding the coconut chaff ratios of 1:20-4:20, belonging to neutral soil. The $\mathrm{pH}$ value of coastal soil was increased by 0.77-1.05 units after adding the coconut chaff. And the soil $\mathrm{pH}$ value was decreased with increasing of adding ratio of the coconut chaff in the treatments with volume ratios of 1:20-4:20. The results indicated that the $\mathrm{pH}$ value of four treatments with volume ratios of 1:20-4:20 were significantly higher than that of the control treatment $(P<0.01)$. However, the differences among the three treatments with adding the coconut chaff ratios of 1:20, 2:20 and 3:20 were not significant $(p>0.05)$.

The soil fertility can be reflected by the content of SOM. Figure 2(a) showed that the contents of organic matter were increased by $11.1 \%-28.1 \%$ after adding the coconut chaff at 1:20-4:20 in coastal soil. And which were increased with increasing of adding ratio of the coconut chaff in the treatments with volume ratios of 1:20-3:20, while slightly decreased in the treatment with adding the coconut chaff ratio of 4:20. The promoting effect of different treatments on the organic matter of coastal soil was 3:20 $>4: 20>2: 20>1: 20$. The results also showed that the SOM of three treatments 
with volume ratios of 2:20-4:20 were significantly higher than that of the control treatment $(P<0.01)$. However, the differences among the three treatments with adding the coconut chaff ratios of 2:20, 3:20 and 4:20 were not significant $(p>0.05)$.

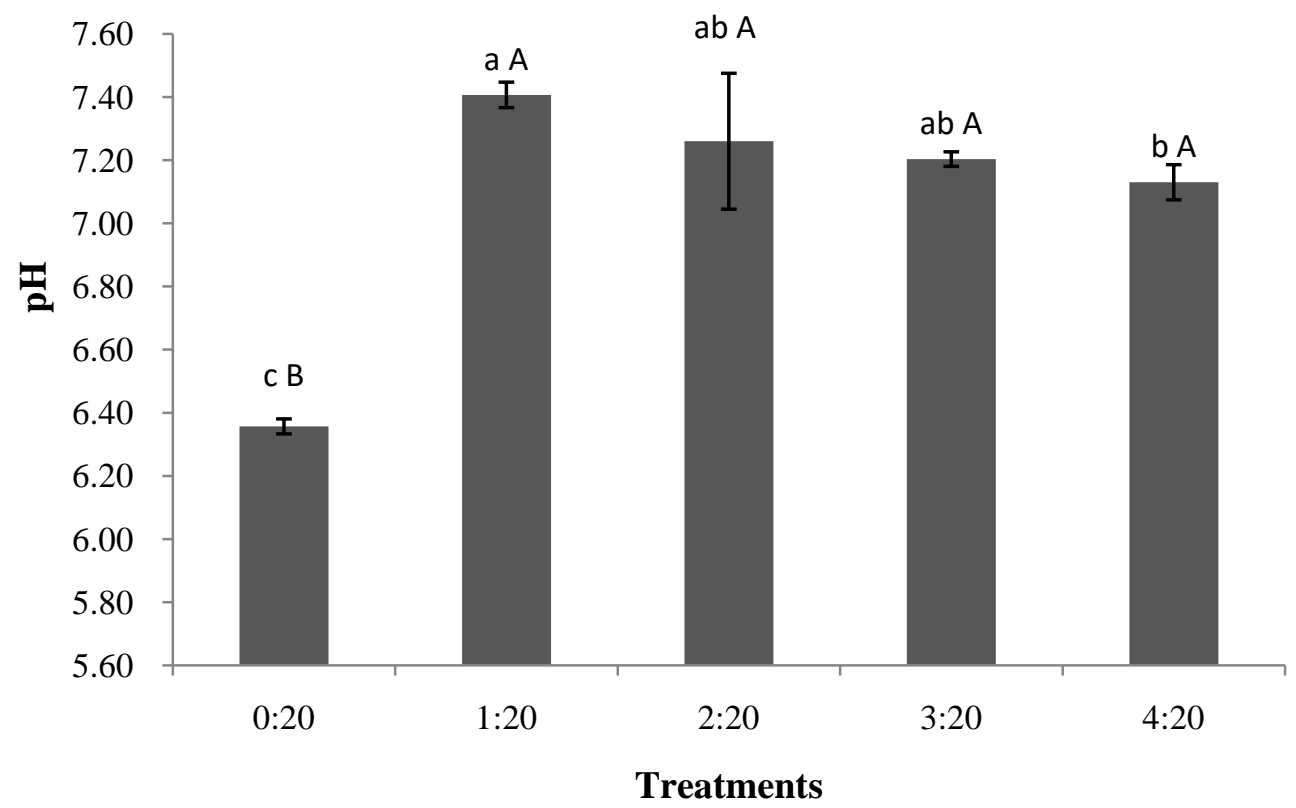

Figure 1. Effect of coconut chaff on the $\mathrm{pH}$ value in coastal soil.

The soil nitrogen is one of the most important nutrient elements on the growth and development of plants. Figure 2(b) showed that the contents of TN were increased by 31.3\%-35.6\% after adding the coconut chaff in coastal soil. The promoting effect of different treatments on the content of TN in coastal saline soil was 2:20 >1:20>3:20>4:20. The results also showed that the contents of TN in four treatments with volume ratios of 1:20-4:20 were significantly higher than that of the control treatment $(P<0.01)$. However, the differences among the four treatments were not significant $(p>0.05)$.

The influence of the content of AP and AK on the growth and development of plants is very great. Figure 2(c) showed that the contents of AP were increased by $13.0 \%-23.5 \%$ after adding the coconut chaff in coastal soil. And the promoting effect of different treatments on the content of AP in coastal soil was 2:20>4:20 > 3:20>1:20. The results also showed that the contents of AP in three treatments with volume ratios of 2:20-4:20 were significantly higher than that of the control treatment $(P<0.05)$. However, the differences among the three treatments were not significant $(p>$ 0.05). Figure 2(d) showed that the contents of AK were increased by $9.9 \%-44.8 \%$ after adding the coconut chaff in coastal soil. And the promoting effect of different treatments on the content of AK in coastal saline soil was 4:20 > $3: 20>2: 20>1: 20$. The results also showed that the contents of AK in three treatments with volume ratios of 2:20-4:20 were significantly higher than that of the control treatment $(P<0.01)$.

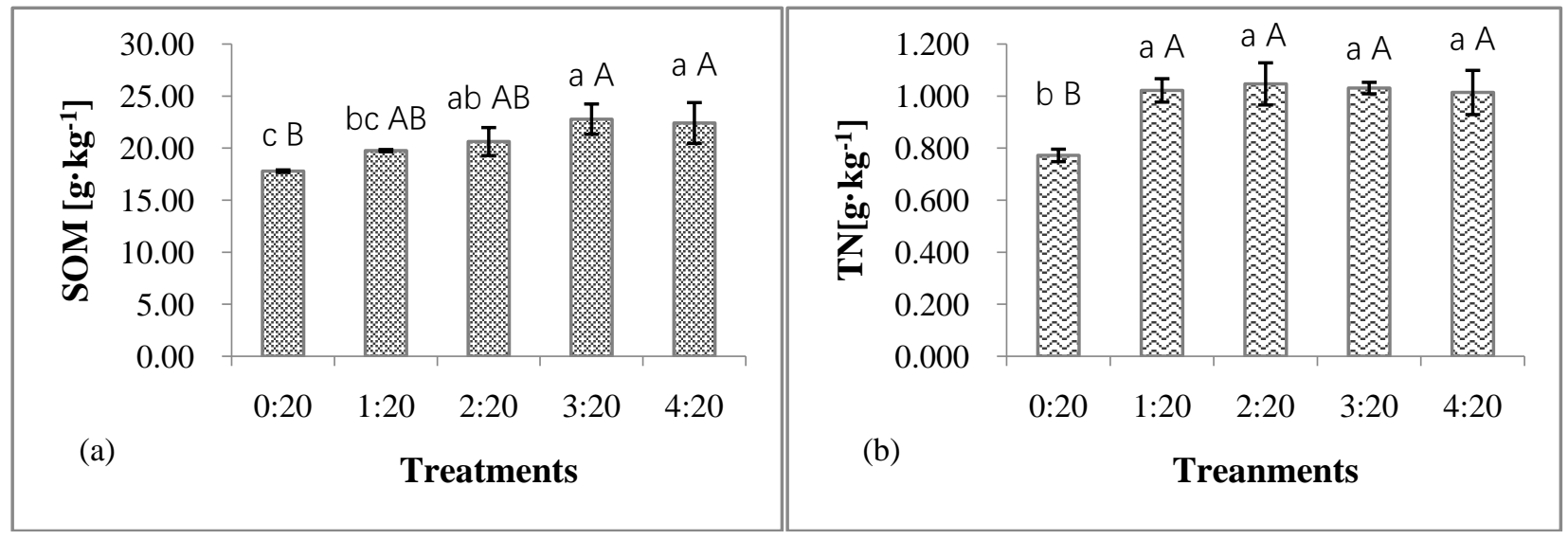




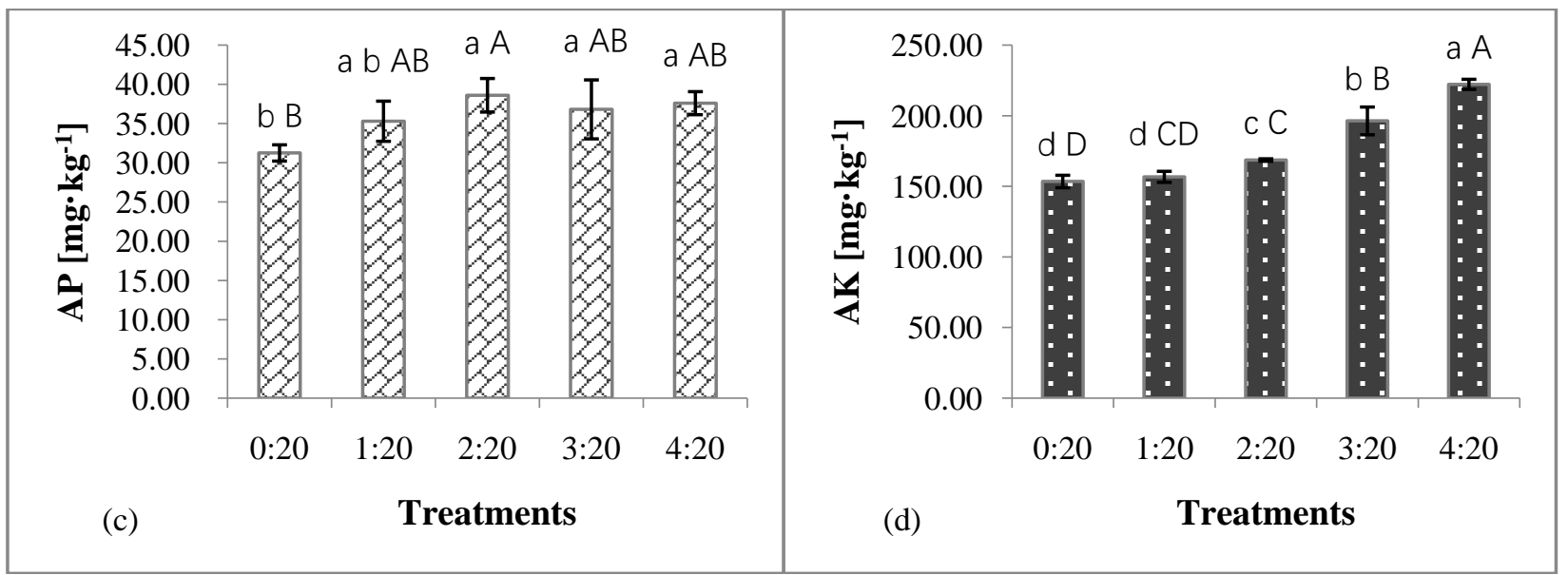

Figure 2. Effect of coconut chaff on nutrient contents in coastal soil.

Soil enzyme is one of the most active parts of soil components. It is an important index for evaluation of soil fertility, and can reflect the status of soil quality and the ecological environment situation [4-6]. Soil enzyme activities play a key role in nutrients recycling, making them accessible to plants and microorganisms [7-9]. UE is closely related to the transformation of nitrogen in the soil, and can reflect part of soil productivity. Soil UE activity was used to characterize the nitrogen status of soil. Figure 3(a) showed that the UE activity of coastal soil was increased by $0.3 \%-15.1 \%$ after adding the coconut chaff in water spinach plantation under conditions without chemical fertilizer utilization. And the soil UE activity was increased with increasing of adding ratio of the coconut chaff in the treatments with volume ratios of 1:20-4:20. The result also indicated that the UE activity of treatment with volume ratios of 4:20 was significantly higher than that of the control treatment $(P<0.05)$.

\begin{tabular}{|c|c|c|c|c|c|c|c|c|c|c|c|c|c|}
\hline 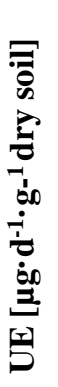 & $\begin{array}{r}600.00 \\
500.00 \\
400.00 \\
300.00 \\
200.00 \\
100.00 \\
0.00\end{array}$ & 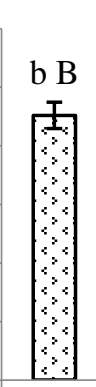 & $\begin{array}{l}\mathrm{b} \text { B } \\
{\left[\begin{array}{l}7 \\
3 \\
3 \\
3 \\
3\end{array}\right]}\end{array}$ & $\begin{array}{l}\mathrm{b} A B \\
\\
\\
\end{array}$ & 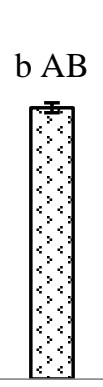 & $\begin{array}{c}\text { a A } \\
7 \\
7 \\
\\
\\
3 \\
\end{array}$ & 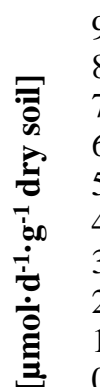 & $\begin{array}{l}9.00 \\
8.00 \\
7.00 \\
6.00 \\
5.00 \\
4.00 \\
3.00 \\
2.00 \\
1.00 \\
0.00\end{array}$ & $\begin{array}{l}\mathrm{d} C \\
\mathrm{~T} \\
\text { : }\end{array}$ & a A & 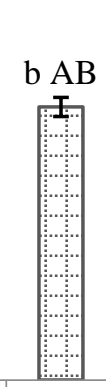 & bc B & $\begin{array}{l}\text { с BC } \\
\text { at } \\
\text { at }\end{array}$ \\
\hline (a) & & $0: 20$ & \multicolumn{3}{|c|}{ Treatments } & 4:20 & \multicolumn{2}{|c|}{ (b) } & $0: 20$ & \multicolumn{3}{|c|}{ Treatments } & $4: 20$ \\
\hline 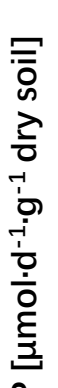 & $\begin{array}{r}14.00 \\
12.00 \\
10.00 \\
8.00 \\
6.00 \\
4.00 \\
2.00\end{array}$ & $\begin{array}{c}\text { ab A } \\
\mathrm{A}^{\mathrm{A}}\end{array}$ & $\begin{array}{l}\mathrm{ab} A \\
\mathrm{~A} \\
\mathrm{~A}\end{array}$ & $\begin{array}{l}\mathrm{a} A \\
\mathrm{~A} \\
\mathrm{~b}\end{array}$ & $\begin{array}{c}\mathrm{ab} A \\
\mathrm{~A}\end{array}$ & $\begin{array}{l}\text { b A } \\
\text { मे } \\
\text { म }\end{array}$ & 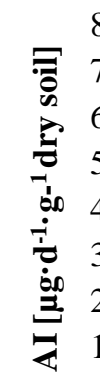 & $\begin{array}{l}80 \\
70 \\
60 \\
50 \\
40 \\
30 \\
20 \\
10\end{array}$ & $\begin{array}{l}\mathrm{d} \mathrm{C} \\
\mathrm{T} \\
3\end{array}$ & $\begin{array}{l}\text { с в } \\
\text { य. }\end{array}$ & $\begin{array}{l}\mathrm{b} \text { B } \\
\mathrm{A}\end{array}$ & $\begin{array}{l}\text { a A } \\
3 \\
3 \\
3\end{array}$ & $\begin{array}{l}\text { b B } \\
\text { a } \\
3\end{array}$ \\
\hline 운 & & $0: 20$ & $1: 20$ & $2: 20$ & $3: 20$ & $4: 20$ & & & $0: 20$ & $1: 20$ & $2: 20$ & $3: 20$ & $4: 20$ \\
\hline (c) & & & & eatmeI & & & (d) & & & & eatmen & & \\
\hline
\end{tabular}

Figure 3. Effect of coconut chaff on the enzyme activities in coastal soil. 
The CAT activity, which is related to soil respiration and soil microbial activity, can decompose the harmful hydrogen peroxide to water and oxygen during respiration, and reduce the harm of hydrogen peroxide to plants. Figure 3(b) showed that the catalase activity of coastal soil was increased by $18.7 \%-35.1 \%$ after adding coconut chaff in water spinach plantation. And the soil CAT activity was decreased with increasing of adding ratio of coconut chaff in the four treatments with volume ratios of 1:20-4:20. However, the CAT activities in four treatments were significantly higher than that of the control treatment $(P<0.01)$.

Phosphatase can decompose organic phosphorus compounds and provide effective phosphorus for plant growth. The soil phosphatase activity can be used to characterize the soil fertility status, especially the status of phosphorus [10]. Figure 3(c) showed that the ACP activity of coastal soil was slightly increased after adding the coconut chaff in water spinach plantation, but the promoting effect was not significant $(p>0.05)$.

Soil invertase can break down sucrose which cannot be directly absorbed by plants into glucose and fructose. It plays an important role for increasing soluble nutrients in soil [11]. Soil invertase activity is often used to characterize soil maturation and fertility. Figure 3(d) showed that the AI activity of coastal soil was increased by $47.9 \%-157.8 \%$ after adding the coconut chaff in water spinach plantation. And the soil AI activity was increased with increasing of adding ratio of coconut chaff in the treatments with volume ratios of 1:20-3:20, while slightly decreased in the treatment with volume ratio of 4:20. The promoting effect of different treatments on AI activity of coastal soil was 3:20 > 2:20 > $4: 20>1: 20>0: 20$. And the AI activities in the four treatments with volume ratios of 1:20-4:20 were significantly higher than that of the control treatment $(P<0.01)$.

\section{Conclusions}

The coconut chaff could not only improve the $\mathrm{pH}$ value, increase the contents of organic matter, total nitrogen, available phosphate and available potassium and enzyme activities of coastal soil, but also promote the growth of water spinach. Especially, the treatments with the addition ratios of 2:20-4:20 could significantly improve the soil $\mathrm{pH}$ value and increase the soil nutrient contents and enzyme activities $(p<0.05)$. This demonstrates that adding the coconut chaff in the right proportion can improve the physicochemical properties of the coastal soil and provide a favorable soil environment for crop growth and achieve the purpose of improvement on coastal soil.

\section{Acknowledgements}

This work was financially supported by the Hainan Provincial Natural Science Foundation of China (320RC695) and Central Public-interest Scientific Institution Basal Research Fund for Chinese Academy of Tropical Agricultural Sciences (1630042017005, 1630042017006).

\section{References}

[1] Qiu, C. M. (2019). Enhancement Technology on Soil Organic Matter. Journal of Changjiang Vegetables, 3, 69-71.

[2] Hua, K., Wang, D., Guo, X., Guo, Z. (2014). Carbon Sequestration Efficiency of Organic Amendments in a Long-Term Experiment on a Vertisol in Huang-Huai-Hai Plain, China. PLoS ONE, 9(9), e108594.

[3] Zhang, W., Xu, M., Wang, X., Huang, Q., Nie, J., Li, Z., Li, S., Hwang, W., and Bo Lee, K. (2012). Effects of Organic Amendments on Soil Carbon Sequestration in Paddy Fields of Subtropical China. Journal of Soils and Sediments, 12, 457-470.

[4] Shan, Q., Yu, Y., Zhang J., and Yu J. (2008). Soil Enzyme Activities and Their Indication for Fertility of Urban Forest Soil. Frontiers of Environmental Science and Engineering, 2(2), 218-223.

[5] Lopez-Aizpun, M., Arango-Mora, C., Santamaria, C., Lasheras, E., Santamaria, J. M., Ciganda, V. S., Cardenas, L. M., Elustondo, D. (2018). Atmospheric ammonia concentration modulates soil enzyme and microbial activity in an oak forest affecting soil microbial biomass. Soil Biology \& Biochemistry, 116, 378-387.

[6] Singh, K. (2016). Microbial and enzyme activities of saline and sodic soils. Land Degradation \& Development, 27, 706-718.

[7] Yu, P. J., Liu, S. W., Han, K. X., Guan, S. C., Zhou, D. W. (2017). Conversion of cropland to forage land and grassland increases soil labile carbon and enzyme activities in northeastern China. Agriculture, Ecosystems \& Environment, 245 , 83-91.

[8] Raiesi, F. and Salek-Gilani, S. (2018). The potential activity of soil extracellular enzyme as an indicator for ecological restoration of rangeland soils after agricultural abandonment. Applied Soil Ecology, 126, 140-147.

[9] Ai, C., Liang, G., Sun, J., He, P., Tang, S., Yang, S., Zhou, W., Wang, X. (2015). The alleviation of acid soil stress in rice by inorganic or organic ameliorants is associated with changes in soil enzyme activity and microbial community composition. Biology and Fertility of Soils, 51, 465-477.

[10] Krämer, S. and Green, D. M. (2000). Acid and Alkaline Phosphatase Dynamics and Their Relationship to Soil Microclimate in a Semiarid Woodland. Soil Biology \& Biochemistry, 32, 179-188.

[11] Gianfreda, L., Sannino, F., Violante, A. (1995). Influence of Pesticides on the Behaviour of Free, Immobilized and Soil Invertase. Soil Biology \& Biochemistry, 27, 1201-1208. 